\title{
The Adsorptive Removal of Fluoride from Aqueous Solution by Modified Sludge: Optimization Using Response Surface Methodology
}

\author{
Ying $\mathrm{Li}^{1}{ }^{1,2}$, Shengke Yang ${ }^{1, *}$, Qianli Jiang ${ }^{1}$, Jie Fang ${ }^{1}$, Wenke Wang ${ }^{1}$ and Yanhua Wang ${ }^{1,3}$ \\ 1 Key Laboratory of Subsurface Hydrology and Ecological Effects in Arid Region, Ministry of Education, \\ Chang'an University, Xi'an 710054, China; 15291192057@163.com (Y.L.); jiangqianli123@sina.cn (Q.J.); \\ 18792975240@163.com (J.F.); wenkew@chd.edu.cn (W.W.); yhwang930@foxmail.com (Y.H.) \\ 2 Xi'an Center of Geological Survey, China Geological Survey, Xi'an 710054, China \\ 3 School of Geography and Tourism, Shaanxi Normal University, Xi'an 710054, China \\ * Correspondence: ysk110@126.com; Tel.: +86-135-7200-5085
}

Received: 26 March 2018; Accepted: 14 April 2018; Published: 23 April 2018

\begin{abstract}
The sludge from the water supply plant was investigated to remove fluoride ions from the water. To improve the adsorption ability, the original sludge sample was treated with fuel oxidation, pyrolysis, hydrochloric acid, and sulphuric acid methods, and hydrochloric acid treatment improved the adsorption capacity of the sludge on the fluoride in water significantly, with a maximum adsorption capacity to $140 \mathrm{mg} / \mathrm{kg}$. The adsorption experimental data was the well fitted pseudo-first-order model and the Langmuir isotherms model. SEM images and XRD patterns of the adsorbent were recorded to get a better insight into the adsorption process. The effect of three variables, hydrochloric acid treated sludge (HWS) dose, $\mathrm{pH}$, and initial fluoride concentration were studied using a Box-Behnken statistical experimental design. The model of the adsorption and optimum conditions was investigated using the response surface methodology. The optimum removal efficiency of fluoride can reach $81.153 \%$ under the optimum condition: HWS dose of $14.10 \mathrm{~g} / \mathrm{L}$ and $\mathrm{pH}$ value at 6.12. The effect of co-existing anions and the removal efficiency from the water were also studied. The results suggest that sludge from the water supply plant can be reused as a coagulant for the removal of fluoride from poor quality water.
\end{abstract}

Keywords: fluoride; response surface methodology; water supply plant sludge; adsorption

\section{Introduction}

As a natural element, fluoride is universally present in varied water bodies, and it is considered beneficial up to $0.7 \mathrm{mg} / \mathrm{L}$ but detrimental if it exceeds $1.5 \mathrm{mg} / \mathrm{L}$, which is the limit recommended by the World Health Organization (2004). Fluoride pollution has been a global environmental concern for decades and has caused great concerns due to its widespread nature and threat to human health. Human exposure to over $1.5 \mathrm{mg} / \mathrm{L}$ of fluoride often causes a lot of health problems through drinking water, such as brain damage, dental fluorosis and skeletal fluorosis, and thyroid disorder [1]. Fluoride-polluted surface water and groundwater is ubiquitous, especially in India, Africa, and the southwest of China. Fluoride has been found in groundwater in many parts of the globe, and it is present in at least 25 countries [2,3].

In the past decades, various techniques have been developed to remove excessive fluoride ions from river water, including coagulation-precipitation [4], membrane-based process [5], ion exchange [6], and adsorption $[7,8]$. In generally, adsorption has been regarded as one of the most important and widely used approaches in the defluoridation of wastewater [9]. Many adsorbents have been used for defluoridation, including activated alumina [10], carbonaceous materials [11], activated clay [12], 
rare earth oxides [13], titanium rich bauxite [14], zeolites [15], and modified natural polymers [16]. Recently, alum sludge has been derived from the by-products of the alum plant, which has been used in environment-related fields to reduce soluble phosphate and nitrogen in soil runoff, land-applied organic waste, and adsorption of $\mathrm{F}^{-}$in aqueous systems $[16,17]$. The adsorption characteristics of alum sludge for fluoride varies according to different conditions that have been studied by Sujana [17] and Kim et al. [18]. However, the drinking water plant-produced water supply sludge (WS) [19] in the coagulation process of producing water, whose structure and composition is different from those of alum sludge. Meanwhile, it has not been reported that using WS to remove fluoride from water and the adsorption characteristics of various conditions has not been studied.

In this study, WS was used as an adsorbent for the removal of fluoride. Additionally, the effect of coexistence anion and various conditions, such as $\mathrm{pH}$, dosage, and initial fluoride concentration, was investigated using the response surface methodology (RSM). This work can provide a new orientation for separating fluoride ions from water and offer a positive reference for solid waste recovery.

\section{Materials and Methods}

\subsection{Samples Collection and Treatment}

WS was taken from the Qujiang water supply plant (Xi'an, China) and air-dried in a clean yard, then crushed and sieved to the sizes $(1 \mathrm{~mm})$ and stored in airtight containers until further using. The original sludge sample was treated with following different methods: pyrolysis was accomplished at $873 \mathrm{~K}$ for $60 \mathrm{~min}$ in pyrolysis furnace [11], and the fuel oxidation sludge was yielded by firing at temperatures $873 \mathrm{~K}$ for $6 \mathrm{~h}$ in muffle furnace [20]. To get the hydrochloric acid acidified sludge, the untreated sludge was water-washed twice, then soaked in $5 \%$ hydrochloric acid for $24 \mathrm{~h}$, and the supernatant was filtered off. The sludge was washed with deionized water for 7 to 8 times until it was neutral and was dried at a temperature of about $100{ }^{\circ} \mathrm{C}$. The sulphuric acid acidified was the same process with $5 \% \mathrm{HCl}$ acidified sludge, while the sulphuric acid was used instead of hydrochloric acid [21].

\subsection{Experimental Process}

Adsorption experiments were conducted by Organization for Economic Co-operation and Development (OECD). The adsorbent mixed with solution was placed in the flask with magnetic stirrer (Model 04803-02, Cole-Palmer-Instrument Company, Vernon Hills, IL, USA). The residual fluoride concentration was measured immediately after filtration using the microfiltration membrane. All the experiments were performed in triplicate, and the mean values were reported.

\subsubsection{Reagent and Standard Solutions}

To simulate natural water, fluoride stock solution was prepared by dissolving anhydrous sodium fluoride $\left(99.0 \%\right.$, NaF, Kemiou Chemical Reagent Co. Ltd., Tianjin, China) with distilled water. Standards $\mathrm{F}^{-}$ samples at a required concentration range were prepared using appropriate dilution of the stock solution.

The $\mathrm{pH}$ of the solution was adjusted by adding $0.1 \mathrm{~mol} / \mathrm{L} \mathrm{HCl}$ or $\mathrm{NaOH}$ solutions (Kemiou Chemical Reagent Co. Ltd., Tianjin, China). The $\mathrm{pH}$ values were periodically measured and readjusted until they were constant. The co-existing anions $\left(\mathrm{SO}_{4}{ }^{2-}, \mathrm{NO}_{3}{ }^{-}, \mathrm{SiO}_{3}{ }^{2-}, \mathrm{PO}_{4}{ }^{-}\right.$, ) solution was prepared with corresponding sodium salts to the concentration of $5-10 \mathrm{mg} / \mathrm{L}$.

\subsubsection{Adsorption Kinetics and Isotherm}

Adsorption experiment was carried out with four treated sludges at first. The fluoride removal efficiency of four treated sludges was investigated by using $2 \mathrm{~g}$ sludge and $48 \mathrm{~mL}$ of the $10 \mathrm{mg} / \mathrm{L} \mathrm{F}^{-}$ stock solution in $200 \mathrm{~mL}$ conical flask, respectively, to keep the constant initial fluoride concentration of $2.4 \mathrm{mg} / \mathrm{L}$. 
In order to obtain an appropriate contact time between the HWS and fluoride ions, the samples were taken at time intervals of $2,4,8,16,20,24,30,36,40,48,60$, and $70 \mathrm{~min}$, then allowed to settle, and residual fluoride ion concentration was measured. The kinetics of fluoride adsorption on the HWS was determined under the initial fluoride of $2.4 \mathrm{mg} / \mathrm{L}$ and HWS dose at $12 \mathrm{~g} / \mathrm{L}$ by using two different kinetic models, which are the pseudo-first-order model and pseudo-second-order model [22,23].

Isotherm experiments were conducted for the equilibration time of $70 \mathrm{mins}$ by varying the fluoride concentration from 0.5 to $5 \mathrm{mg} / \mathrm{L}$ and the constant HWS dose at $15 \mathrm{~g} / \mathrm{L}$. The experimental data was fitted to Fruendlich and Langmuir isotherm models [24]. The removal efficiency ( $\eta$ ) of fluoride ions and equilibrium sorption could be obtained by the Equations (1) and (2):

$$
\begin{gathered}
\eta=\frac{C_{0}-C_{e}}{C_{0}} \times 100 \%, \\
Q_{e}=\frac{V\left(C_{0}-C_{e}\right)}{m},
\end{gathered}
$$

where $\eta(\%)$ is the removal efficiency of fluoride ions, $C_{0}, C_{e}$ are the initial and equilibrium concentrations of fluoride ions $(\mathrm{mg} / \mathrm{L}), \mathrm{Q}_{\mathrm{e}}$ is the equilibrium sorption $(\mathrm{mg} / \mathrm{g})$ at equilibrium, $\mathrm{V}(\mathrm{L})$ is the volume of the aqueous solution, and $\mathrm{m}$ is the mass $(\mathrm{g})$ of adsorbent used in the experiments.

\subsubsection{Batch Experiments of Variable Condition}

The main factors affecting the adsorption of HWS were studied by RSM, including sludge doses $(5,10,15 \mathrm{~g} / \mathrm{L})$, initial fluoride concentration $(1,3,5 \mathrm{mg} / \mathrm{L})$, and $\mathrm{pH}(4,7,10)$. RSM is one such statistical technique and is used for designing experiments, building models, evaluating the effects of several variables, and obtaining the optimum conditions for responses with a limited number of planned experiments [25,26].

Initially, the main experiments were conducted according to Box-Behnken design (BBD) to facilitate the modeling and optimization of the process $(n=17)$. Batch experiments for modeling and optimization were conducted according to design matrix presented in Table 1. For each experiment, $100 \mathrm{~mL}$ of solution with desired fluoride concentrations and HWS dose was mixed at $\mathrm{pH}=4,7,10$, for $70 \mathrm{~min}$, respectively. Finally, the supernatant was drained, and fluoride concentration was determined.

\begin{tabular}{|c|c|c|c|c|c|c|}
\hline \multirow{2}{*}{ Run } & \multirow{2}{*}{$x_{1}$-Initial Concentration $(\mathrm{mg} / \mathrm{L})$} & \multirow{2}{*}{$x_{2}-\mathrm{pH}$} & \multirow{2}{*}{$x_{3}$-HWS dose $(\mathrm{g} / \mathrm{L})$} & \multicolumn{2}{|c|}{ Removal Efficiency (\%) } & \multirow{2}{*}{$\varepsilon$} \\
\hline & & & & $Y_{\exp }$ & $\mathbf{Y}_{\text {pre }}$ & \\
\hline 1 & 3 & 10 & 5 & 34.72 & 35.61 & -0.89 \\
\hline 2 & 3 & 4 & 15 & 71.62 & 70.73 & 0.89 \\
\hline 3 & 3 & 7 & 10 & 63.17 & 65.20 & -2.03 \\
\hline 4 & 1 & 7 & 5 & 57.84 & 57.98 & -0.14 \\
\hline 5 & 3 & 10 & 15 & 63.03 & 62.42 & 0.61 \\
\hline 6 & 5 & 4 & 10 & 45.65 & 46.68 & -1.03 \\
\hline 7 & 3 & 7 & 10 & 65.32 & 65.20 & 0.12 \\
\hline 8 & 3 & 7 & 10 & 65.71 & 65.20 & 0.51 \\
\hline 9 & 5 & 7 & 5 & 25.87 & 24.23 & 1.64 \\
\hline 10 & 1 & 4 & 10 & 74.42 & 73.67 & 0.75 \\
\hline 11 & 3 & 7 & 10 & 65.78 & 65.20 & 0.58 \\
\hline 12 & 3 & 7 & 10 & 66.03 & 65.20 & 0.83 \\
\hline 13 & 1 & 10 & 10 & 69.53 & 68.49 & 1.04 \\
\hline 14 & 1 & 7 & 15 & 79.51 & 81.15 & -1.64 \\
\hline 15 & 5 & 10 & 10 & 38.12 & 38.87 & -0.75 \\
\hline 16 & 3 & 4 & 5 & 39.68 & 40.29 & -0.61 \\
\hline 17 & 5 & 7 & 15 & 58.45 & 58.31 & 0.14 \\
\hline
\end{tabular}

Table 1. BBD matrix and its observed and predicted responses.

Note: HWS: hydrochloric acid treated sludge; bbd: Box-Behnken design. $Y_{\text {exp }}$ : the experimental obtained removal efficiency; $\mathrm{Y}_{\text {pre }}$ : the predicted removal efficiency used BBD modeling. BBD: Box-Behnken design. 


\subsubsection{Effect of Co-Existing Anions}

The effect of co-existing anions $\left(\mathrm{SO}_{4}{ }^{2-}, \mathrm{SiO}_{4}{ }^{4-}, \mathrm{PO}_{4}{ }^{3-}, \mathrm{NO}_{3}{ }^{-}\right)$on fluoride adsorption efficiency of WS was also studied at constant fluoride concentration of $2.4 \mathrm{mg} / \mathrm{L}$ and adsorbent dose of $15 \mathrm{~g} / \mathrm{L}$. Anion $\left(\mathrm{SO}_{4}{ }^{2-}, \mathrm{PO}_{4}{ }^{3-}, \mathrm{SiO}_{4}{ }^{4-}\right.$ and $\left.\mathrm{NO}_{3}{ }^{-}\right)$concentrations of $5,10,20,30$, and $50 \mathrm{mg} / \mathrm{L}$ were prepared by dissolving calculated amount of their sodium salt in $2.4 \mathrm{mg} / \mathrm{L}$ fluoride solution.

\subsubsection{The Examination of Removal Efficient from Water}

To testify the removal efficiency of the fluoride ions from water under optimal conditions, the adsorption experiment was studied with three water samples. W1 was collected from the effluent of a typical fluorite tailing pond, and W2 and W3 were collected from the effluent of two different glass processing factories. The concentration of three water samples are shown in Table 2.

Table 2. The water quality of three water samples.

\begin{tabular}{cccc}
\hline Samples & $\mathbf{F}^{-}(\mathbf{m g} / \mathbf{L})$ & $\mathbf{S S}(\mathbf{m g} / \mathbf{L})$ & $\mathbf{p H}$ \\
\hline W1 & 20.2 & 615.0 & 9.10 \\
W2 & 15.3 & 45.0 & 7.40 \\
W3 & 8.6 & 34.0 & 7.42 \\
\hline
\end{tabular}

Note: SS: suspended solid.

\subsection{Analysis}

An ionic-activity meter (PXS-215, Shanghai instrument electric science instrument, Shanghai, China) equipped with combination fluoride-selective electrode (PF-1, Shanghai instrument electric science instrument, Shanghai, China) was employed for the measurement of fluoride ion concentration. The $\mathrm{pH}$ was measured with $\mathrm{pH}$ meter (DELTA320, Mettler Toldedo, Zurich, Switzerland). The compositions of sludge were analyzed using X-ray diffraction (XRD, Shimadzu, Kyoto, Japan), and the surface morphologies of sludge were examined using scanning electron microscope (SEM, JSM-6700F, FEI NanoPorts, Hillsboro, AL, USA). The surface area, pore area, pore volume, and average pore size determinations were carried out by $\mathrm{N}_{2}$ adsorption isotherms using a Micrometrics ASAP 2020K surface area analyzer (Micromeritics Instrument Corp., Atlanta, GA, USA).

\section{Results and Discussion}

\subsection{Effects of Four Treated Sludges when Removing Fluoride}

The compositions of WS for the experiment are shown in Table 3. The WS contained large number of $\mathrm{Al}_{2} \mathrm{O}_{3}$ and $\mathrm{Fe}_{2} \mathrm{O}_{3}$ through the coagulation with the addition of polyaluminum chloride (PAC), aluminum sulfate $\left(\mathrm{Al}_{2}\left(\mathrm{SO}_{4}\right)_{3}\right)$, and ferric chloride $\left(\mathrm{FeCl}_{3}\right)$ in the process of producing water. $\mathrm{SiO}_{2}$ was brought by the sludge in the settlement process. Compared to the WS, alum sludge coming from the alum plant [17] contained almost the same content of $\mathrm{Al}_{2} \mathrm{O}_{3}$ and $\mathrm{Fe}_{2} \mathrm{O}_{3}$ but less $\mathrm{SiO}_{2}$ and more $\mathrm{TiO}_{2}$, which was decided by the raw materials and the production process. In order to improve the adsorption ability, the original sludge sample was treated with different methods. Meanwhile, fluorine removal experiments were carried out with the treated samples. The results shown in Figure 1 indicate that acid treatment can improve the ability of sludge to adsorb fluoride from water. Compared to other methods of treatment with original sludge, the sludge after acid treatment has the best efficiency, and $\mathrm{HCl}$-acidified sludge is better than $\mathrm{H}_{2} \mathrm{SO}_{4}$. The fuel oxidation treatment can slightly improve the removal efficiency, while the pyrolysis displays a little suppression (Figure 1). 
Table 3. Composition of the chemical constituents in WS.

\begin{tabular}{ccc}
\hline Chemical Composition & WS (\%) & Alum Sludge(\%) [17] \\
\hline $\mathrm{Al}_{2} \mathrm{O}_{3}$ & 47.56 & 47.20 \\
$\mathrm{SiO}_{2}$ & 28.54 & 1.60 \\
$\mathrm{Fe}_{2} \mathrm{O}_{3}$ & 4.30 & 7.18 \\
$\mathrm{TiO}_{2}$ & 1.47 & 20.65 \\
$\mathrm{Cl}^{-}$ & 2.14 & - \\
$\mathrm{LOI}$ & 14.32 & 19.00 \\
\hline \multicolumn{3}{c}{ Note: WS: water supply sludge. }
\end{tabular}

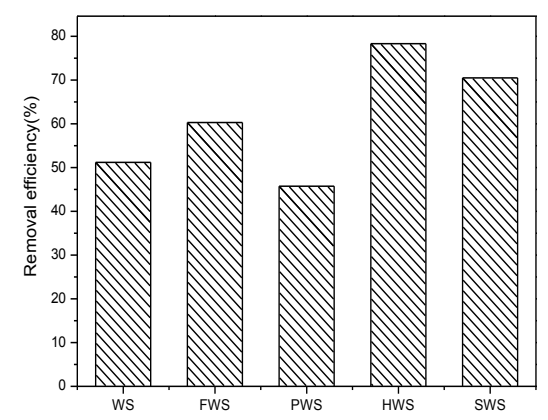

Figure 1. Removal efficiency of fluoride by different treated WS. Note: WS: water supply sludge, FWS: fuel oxidation-WS, PWS: pyrolysis WS, HWS: hydrochloric acid-WS, SWS: sulphuric acid-WS).

\subsection{Equilibrium and Kinetics of Adsorption}

Adsorption kinetics, demonstrating the solute uptake rate, is one of the most important characters that represent the adsorption efficiency of the HWS. Two possible models of kinetics were used to fit the experimental results (Figure 2a): (1) pseudo-first-order model and (2) pseudo-second-order model [27,28].

As shown in Table 4, the pseudo-first-order model has a better fit with the experimental data with the higher squared correlation coefficients $\left(R^{2}=0.9894\right)$. The adsorption reaction is fast during the initial $40 \mathrm{~min}$, and equilibrium was reached around $70 \mathrm{~min}$. This result was in agreement with the equilibrium time found for alum sludge and quartz, which are reported in other studies $[17,24]$.

The analysis of Langmuir and Freundlich isotherm models [29] were presented in Figure $2 b$ and Table 5. The $\mathrm{R}_{\mathrm{L}}$ values in Langmuir model are favorable $\left(0<\mathrm{R}_{\mathrm{L}}<1\right)$ [30]. The higher regression correlation coefficient (0.9959) was observed for Langmuir model, indicating that the Langmuir model was the most suitable for describing the adsorption equilibrium, meaning the formation of fluoride ion at the outer surface of the HWS was monolayer coverage [22].

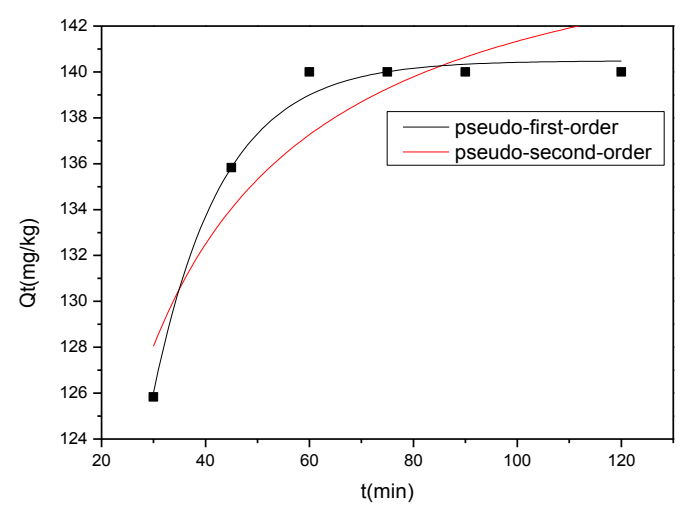

(a)

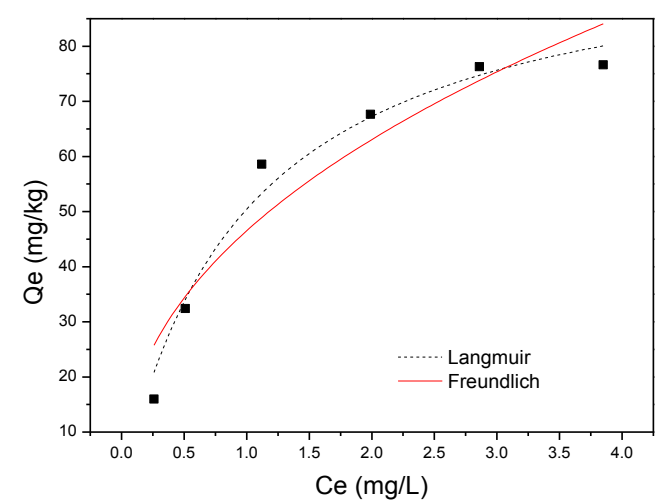

(b)

Figure 2. The fitted plot of (a) kinetics and (b) isotherm models. 
Table 4. Kinetic parameters and statistical parameters of the two kinetic models.

\begin{tabular}{cccccccc}
\hline \multirow{2}{*}{ Adsorbent } & \multirow{2}{*}{$\mathbf{Q}_{\mathrm{e}, \exp }(\mathbf{m g} / \mathbf{g})$} & \multicolumn{3}{c}{ Pseudo-First Order } & \multicolumn{3}{c}{ Pseudo-Second Order } \\
\cline { 3 - 8 } & & $\mathbf{R}^{\mathbf{2}}$ & $\mathbf{K}_{\mathbf{1}} \mathbf{( 1 / h )}$ & $\mathbf{Q}_{\mathrm{e}, \mathrm{cal}}(\mathbf{m g} / \mathbf{g})$ & $\mathbf{R}^{\mathbf{2}}$ & $\left.\mathbf{K}_{\mathbf{2}} \mathbf{( k g} / \mathbf{m g} \cdot \mathbf{h}\right)$ & $\mathbf{Q}_{\mathrm{e}, \mathrm{cal}}(\mathbf{m g} / \mathbf{g})$ \\
\hline HWS & 0.1402 & 0.9894 & 0.0757 & 0.1405 & 0.8286 & 1.5 & 0.1479 \\
\hline
\end{tabular}

Note: $Q_{e, e x p}$ refers to actual equilibrium adsorption capacity; $Q_{e, c a l}$ refers to the fitted theoretical equilibrium adsorption capacity; $\mathrm{K}_{1}, \mathrm{~K}_{2}$ is the rate constant of the kinetics models.

Table 5. Adsorption isotherm constants for fluoride adsorption onto HWS.

\begin{tabular}{ccccccc}
\hline \multicolumn{3}{c}{ Langmuir } & \multicolumn{4}{c}{ Freundlich } \\
\hline $\mathrm{Q}_{\mathrm{m}}(\mathrm{mg} / \mathrm{g})$ & $\mathrm{b}(\mathrm{L} / \mathrm{mg})$ & $\mathrm{R}^{2}$ & $\mathrm{R}_{\mathrm{L}}$ & $\mathrm{K}_{\mathrm{F}}(\mathrm{mg} / \mathrm{g}) \cdot(\mathrm{L} / \mathrm{mg})^{1 / \mathrm{n}}$ & $1 / \mathrm{n}$ & $\mathrm{R}^{2}$ \\
0.24643 & 1.8547 & 0.9959 & 0.7294 & 0.1455 & 0.4165 & 0.9537 \\
\hline
\end{tabular}

\subsection{Adsorption Mechanism Analysis}

\subsubsection{Surface Area Analysis}

To further explore the surface area of the untreated and hydrochloric acid water sludge samples, the BET adsorption experiment was employed. Adsorption-desorption $\mathrm{N}_{2}$ isotherms are shown in Figure 3, and the surface area and pore size data are listed in Table $6 . \mathrm{N}_{2}$ adsorption-desorption loops were not closed, because when the experiments were below 0.15 Pa pressure, irreversible adsorption occurred, and the adsorbed $\mathrm{N}_{2}$ could not be desorbed. This indicated that there was a strong adsorption potential in the micropores of the HWS, while the WS sample does not exist in this case, and Table 6 shows that the average pore size of HWS is $3.23694 \mathrm{~nm}$, which is relatively smaller than the WS of $8.88669 \mathrm{~nm}$, which also revealed the that there is no adsorption potential in the micropores of WS. In addition, the surface area and pore volume of HWS improved 6.82 and 7.93 times, respectively, compared to the untreated WS, so the adsorption capacity of HWS is higher than WS is reasonable.

Table 6. The surface area, pore volume, and pore size of the WS and HWS.

\begin{tabular}{cccc}
\hline Samples & Surface Area $\left(\mathbf{m}^{2} / \mathbf{g}\right)$ & Pore Volume $\left(\mathbf{m}^{3} / \mathbf{g}\right)$ & Average Pore Size $(\mathbf{n m})$ \\
\hline WS & 6.85680 & 0.000723 & 8.88669 \\
HWS & 53.59230 & 0.006453 & 3.23694 \\
\hline
\end{tabular}

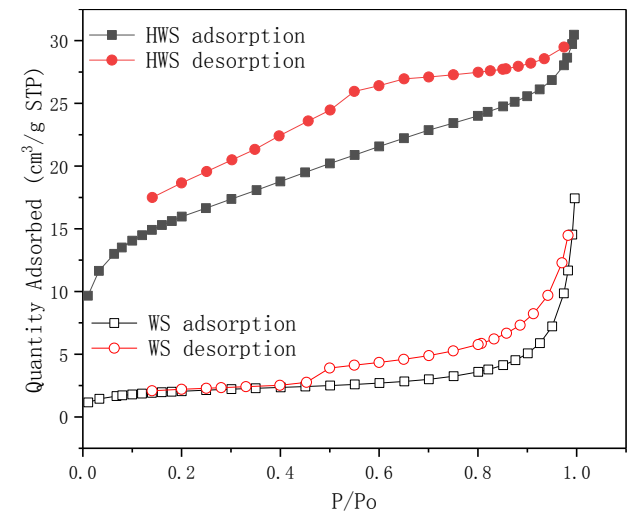

Figure 3. Adsorption-desorption isotherm. (STP: stardard tempreture $\left(273.15 \mathrm{~K}\left(0^{\circ} \mathrm{C}\right)\right.$ and pressure (100 kPa)). 


\subsubsection{SEM and XRD Studies}

The SEM images of HWS before and after absorption are shown in Figure 4. There is no evident change observed after the adsorption. The XRD results (Figure 5) also revealed that only peaks intensity changed, while the diffractograms are similar, and no important changes in the structure of the adsorbent after adsorption are observed, indicating that the process was mainly physical adsorption-dominated. The identified compounds were $\mathrm{K}_{1.2} \mathrm{Al}_{4} \mathrm{Si}_{8} \mathrm{O}_{2}(\mathrm{OH})_{2} \cdot 4 \mathrm{H}_{2} \mathrm{O}, \mathrm{TiFeCl}_{3}, \mathrm{SiO}_{2}$, $\mathrm{Al}_{2} \mathrm{SiO}_{5},(\mathrm{Mg}, \mathrm{Fe})_{2} \mathrm{SiO}_{4}, \mathrm{Fe}_{0.4} \mathrm{Mg}_{0.76} \mathrm{SiO}_{3}$, and $(\mathrm{Mg}, \mathrm{Al}, \mathrm{Fe})_{6}(\mathrm{Si}, \mathrm{Al})_{4} \mathrm{O}_{10}(\mathrm{OH})_{8}$.
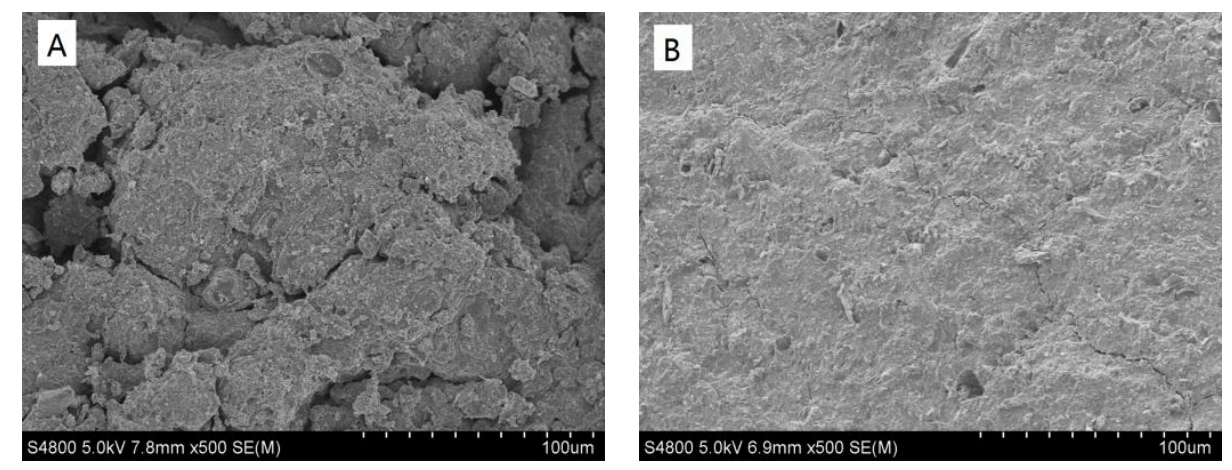

Figure 4. SEM of the adsorbent (A) before adsorption (B) after adsorption.

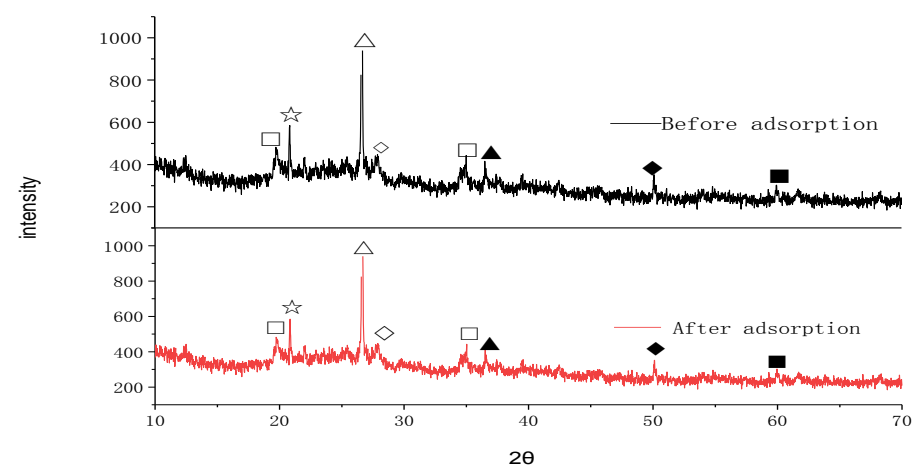

Figure 5. XRD spectra of HWS before and after the adsorption of fluoride, and the identified compounds: $\square \mathrm{K}_{1.2} \mathrm{Al}_{4} \mathrm{Si}_{8} \mathrm{O}_{2}(\mathrm{OH})_{2} \cdot 4 \mathrm{H}_{2} \mathrm{O}$, $\mathrm{TiFeCl}_{3}, \triangle \mathrm{SiO}_{2}, \diamond \mathrm{Al}_{2} \mathrm{SiO}_{5}, \Delta\left(\mathrm{Mg}, \mathrm{Fe}_{2} \mathrm{SiO}_{4}\right.$, $\checkmark \mathrm{Fe}_{0.4} \mathrm{Mg}_{0.76} \mathrm{SiO}_{3}$, and $\mathbf{\square}(\mathrm{Mg}, \mathrm{Al}, \mathrm{Fe})_{6}(\mathrm{Si}, \mathrm{Al})_{4} \mathrm{O}_{10}(\mathrm{OH})_{8}$.

\subsection{Effects of Variable Conditions on the Adsorption of Fluoride}

The effects of variable conditions on fluoride removal were studied using RSM. As mentioned earlier, RSM based on BBD was employed to investigate the effects of three independent variables, HWS dose, $\mathrm{pH}$, and initial concentration on the adsorption of fluoride by HWS. The BBD factorial design along with five replicates at central points is presented in Table 1. Design Expert 8.0.6 software (Stat-Ease Corporation, Minneapolis, MN, USA) was used for experimental design and analysis. Experimental data were fitted to a second-order polynomial model [31]:

$$
\mathrm{Y}=b_{0}+\sum_{\mathrm{i}=1}^{\mathrm{k}} \mathrm{b}_{\mathrm{i}} \mathrm{x}_{\mathrm{i}}+\sum_{\mathrm{i}=1}^{\mathrm{k}} \mathrm{b}_{\mathrm{ii}} \mathrm{x}_{\mathrm{i}}^{2}+\sum_{\mathrm{i}=1}^{\mathrm{k}-1} \sum_{\mathrm{j}=\mathrm{i}+1}^{\mathrm{k}} \mathrm{b}_{\mathrm{ij}} \mathrm{x}_{\mathrm{i}} \mathrm{x}_{\mathrm{j}}+\varepsilon,
$$

in which $\mathrm{Y}$ is the predicted response (Removal efficiency in \%) used as dependent variable, $x_{i}$ and $x_{j}$ are the in dependent variables, $b_{0}$ is the constant coefficient, $b_{i}$ is the coefficient that determines the influence of variable $i$ in the response, $b_{i j}$ is the coefficient that determines the effect of interaction 
between variables $i$ and $j, b_{i i}$ is the parameter that determines the shape of the curve, and $k$ is the number of variables studied [25,32].

RSM model and its validation based on the experimental results are presented in Table 2. Based on the experimental data, regression models using a second-order polynomial were represented by Equation (4), which was developed, after which statistically insignificant coefficients ( $p$-value greater than 0.1 ) were excluded from the analysis.

$$
\mathrm{Y}=7.794-5.965 \mathrm{x}_{1}+7.806 \mathrm{x}_{2}+7.825 \mathrm{x}_{3}+0.273 \mathrm{x}_{1} \mathrm{x}_{3}-0.640 \mathrm{x}_{1}^{2}-0.635 \mathrm{x}_{2}^{2}-0.289 \mathrm{x}_{3}^{2}
$$

The analysis of variance (ANOVA) for the proposed model and corresponding $p$-values and F-values for assessing the significance of the regression coefficients are presented in Table 7. A $p$-value of model less than 0.05 implies that the proposed model well predicts the experimental results at $5 \%$ confidence interval [21]. A large $p$-value for lack of fit $(>0.05)$ is preferred, as it measures the model failure in representing data points in the experimental domain [33]. In this case, the $p$-value of lack of fit is 0.1792 , implying that lack of fit of the model is insignificant. Adequate precision (AP) is the ratio of the predicted responses from the design points to their average standard deviation, which, for a good model fit, its desired value is 4 or more [21]. The ratio of 48.388 implies that the model is acceptable. The overall prediction performance of the model is described by coefficient of determination $\left(R^{2}\right)$. A high $R^{2}$ value, close to 1 , is desirable to ensure a satisfactory adjustment of the model to the experimental data [26]. The value of $R^{2}=0.9957$ and a reasonable agreement with $R^{2}$ adjusted is necessary [25,34]. In the present models, the values of $R^{2}$ adjusted $=0.9901$ was close to $R^{2}$, indicating high significance of the model.

Table 7. Analysis of variance (ANOVA) test for removal (\%) of fluoride.

\begin{tabular}{ccccccc}
\hline Source & Sum of Squares & df & Mean Square & F-value & $p$-value $p>$ F & Significance \\
\hline Model & 3782.08 & 9 & 420.23 & 178.60 & $<0.0001$ & significant \\
A-initial & 1602.06 & 1 & 1602.06 & 680.88 & $<0.0001$ & \\
concentration & & & & & & \\
B-pH & 84.31 & 1 & 84.31 & 35.83 & 0.0006 & \\
C-HWS dose & 1638.78 & 1 & 1638.78 & 696.48 & $<0.0001$ & \\
AB & 1.74 & 1 & 1.74 & 0.74 & 0.4180 & \\
AC & 29.76 & 1 & 29.76 & 12.65 & 0.0093 & 0.2753 \\
BC & 3.29 & 1 & 3.29 & 1.40 & 0.0111 & \\
$\mathrm{~A}^{2}$ & 27.56 & 1 & 27.56 & 11.71 & 0.0001 & not \\
$\mathrm{B}^{2}$ & 137.45 & 1 & 137.45 & 58.42 & & \\
$\mathrm{C}^{2}$ & 219.85 & 1 & 219.85 & 93.44 & & \\
Residual & 16.47 & 7 & 2.35 & & & \\
Lack of Fit & 11.05 & 3 & 3.68 & 2.72 & & \\
Pure Error & 5.42 & 4 & 1.36 & & \\
Cor Total & 3798.55 & 16 & &
\end{tabular}

A plot of the residuals was also used to assess the adequacy of the model. The residual plots of the models are presented in Figure 6a. The residuals are normally distributed if the points on the plot follow a straight line [31]. As Figure 6a illustrates, the assumption of normality is satisfied for the models [26]. Figure $6 \mathrm{~b}$ presents the observed and predicted values. The statistical significances of the models are evident from Figure $6 \mathrm{a}$, as observed and predicted values fit each other well. The statistical model can be used to predict the removal efficiency in this experiment in the range above. 


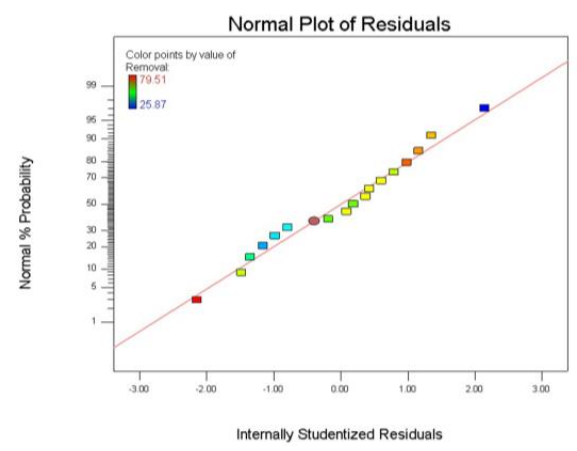

(a)

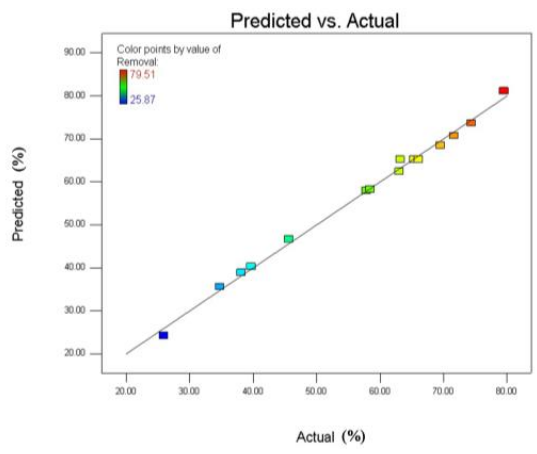

(b)

Figure 6. Assess the adequacy of the model used the plot of the residuals (a) Normal probability of residuals and (b) Predicted versus actual values.

Response surface graphs presented in Figure 7 demonstrate the effects of variables and their interactive effects on the removal of fluoride. These plots are generated as a function of two variables at the same time, keeping the third variable at a centre level. As shown in (a) and (b), the increase of initial fluoride concentration leads to the decrease of final efficiency. As shown in (c), the removal efficiency increased as the HWS dose increased under the same $\mathrm{pH}$. The increase in fluoride adsorption was possibly attributed to the increase in availability of $\mathrm{F}^{-}$due to the presence of a greater number of active sites [35,36]. Considering initial concentration $=3 \mathrm{mg} \cdot \mathrm{L}^{-1}$, the WHO standard for permissible limit of fluoride in water $\left(\leq 1.5 \mathrm{mg} \cdot \mathrm{L}^{-1}\right)$, which would be fulfilled with HWS $\left(\geq 6.17 \mathrm{~g} \cdot \mathrm{L}^{-1}\right)$ in the neutral condition of the present work, can be less at $\mathrm{pH}=6$. However, the effect of removal efficiency of fluoride was more prominent by initial concentration compared to HWS dose and $\mathrm{pH}$ from (a) and (b), meaning initial concentration of fluoride has an adverse effect on its removal. Samarghandi reported a similar result in adsorption of fluoride [31]. At low initial concentration, most of fluoride will interact with the binding sites of the adsorbent, resulting in higher removal percentage. On the other hand, at high initial concentration, only some of the ions will combine with the finite available sites for binding [37].

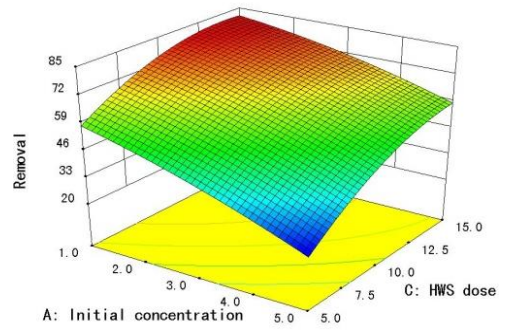

(a)

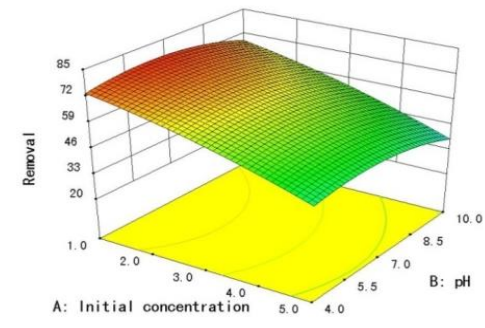

(b)

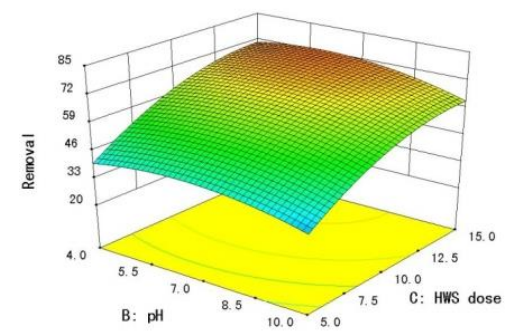

(c)

Figure 7. Response surface graphs: (a) response surface plot for fluoride removal as a function of HWS dose and initial concentration, (b) response surface plot for fluoride removal as a function of $\mathrm{pH}$ and initial concentration, and (c) response surface plot for fluoride removal as a function of HWS dose and $\mathrm{pH}$. 
Usually, $\mathrm{pH}$ has been seen as an important factor influencing adsorption of the crystalline form to the adsorbent. It has been reported that, in case of zeolite and activated alumina, the $\mathrm{pH}$ of zero charge (pHpzc) may vary from 5.5 to about 8.3 [24], and the optimum $\mathrm{pH}$ for maximum adsorption is between 5 and 7 [31,38]. The influence of the initial $\mathrm{pH}$ on the removal efficiency of this study is shown in Figure $7 \mathrm{~b}, \mathrm{c}$. The percentage of fluoride removal remains nearly constant within the $\mathrm{pH}$ range of 4-7. Further increase in the $\mathrm{pH}$ of the solution slightly decreases the removal efficiency. The fluoride uptake capacity of this media is not affected in the $\mathrm{pH}$ range less than or equal to 7 , possibly due to the presence of positively charged and neutral sites at the surface of the adsorbent [24]. The decline at $\mathrm{pH}>7$ may be due to the competition between $\mathrm{OH}^{-}$and $\mathrm{F}^{-}$[39]. This is in agreement with fluoride removal studies on activated alumina by other researchers.

The numerical simulation optimum conditions for removal efficiency of fluoride using HWS were carried by RSM with the help of the desirability function. In this study, the desirability function approach was employed for optimization using Design Expert, which provides several possible options including minimum, maximum, target, within the range, none (only for response), and equal to (factors only) for choosing a desired goal for each variable and response [39]. The average values of confirmation tests in triplicates and predicted by the model under optimum conditions are presented in Table 7. As shown in Table 8, the removal efficiency of confirmation tests was closed to the prediction. The optimum removal efficiency of fluoride can reach $81.153 \%$ under the optimum condition: HWS dose of $14.10 \mathrm{~g} / \mathrm{L}$ and $\mathrm{pH}$ value at 6.12. Meanwhile, the lower initial fluoride concentration is better.

Table 8. Optimum conditions for fluoride removal.

\begin{tabular}{cccccc}
\hline Item & Initial Concentration $(\mathrm{mg} / \mathrm{L})$ & $\mathrm{pH}$ & HWS Dose $(\mathrm{g} / \mathrm{L})$ & Removal $(\%)$ & Desirability \\
\hline Predicted & linear & 6.12 & 14.10 & 81.921 & 0.756 \\
Observed & linear & 6.12 & 14.10 & 81.153 & - \\
\hline
\end{tabular}

\subsection{Effect of Co-Existing Anions}

As we all know, water contains other anions such as sulfate, phosphate, nitrate, and silicate in addition to fluoride. The results for the removal efficiency of HWS with concentration of each anion are shown in Figure 8. Some studies showed that the presence of other co-existing ions in water had an effect on fluoride removal $[17,24,40,41]$. It was observed that $\mathrm{SO}_{4}{ }^{2-}, \mathrm{PO}_{4}{ }^{3-}, \mathrm{SiO}_{4}{ }^{4-}$, and $\mathrm{NO}^{3-}$ ions showed a negative effect on removal of fluoride. The fluoride adsorption efficiency of the adsorbent decreased from about $80 \%$ to $14 \%$ in case of silicate and $29 \%$ in phosphate, and although the sulfate and nitrate showed slight influence on fluoride removal, the removal efficiency still decreased from $80 \%$ to $65 \%$ for nitrate and $46 \%$ for sulfate. This can be due to the competition between the anions and fluoride [41]. The competition ability of four anions followed the order $\mathrm{SiO}_{4}{ }^{4-}>\mathrm{PO}_{4}{ }^{3-}>\mathrm{SO}_{4}{ }^{2-}>\mathrm{NO}_{3}{ }^{-}$; the results are in good agreement with similar work done by others [24] for activated alumina.

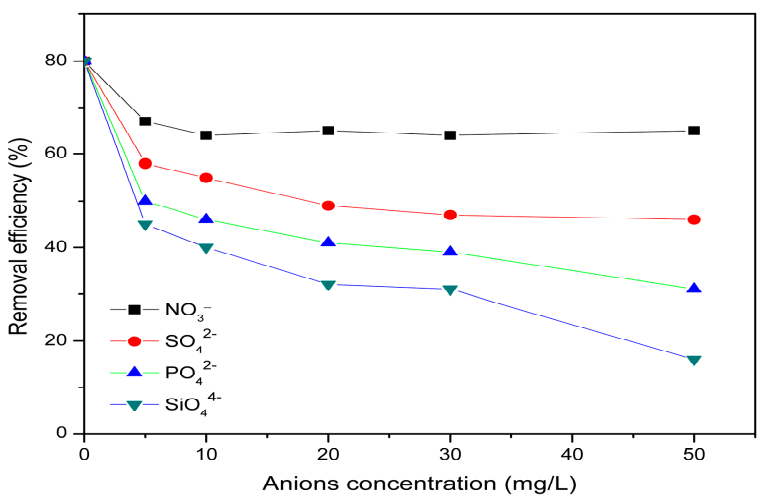

Figure 8. Effect of co-ions on adsorption. 


\subsection{The Adsorption Efficiency from Water}

The adsorption experiment results with wastewater samples are shown in Table 9. To examine the optimal removal efficiency, the $14.1 \mathrm{~g} / \mathrm{L}$ of adsorbent was first added. Results showed that the removal efficiencies were $79.21 \%$ for $\mathrm{W} 1,79.84 \%$ for $\mathrm{W} 2$, and $80.67 \%$ for $\mathrm{W} 3$, respectively, which was in agreement with the results obtained from RSM analysis, i.e., the removal efficiency for the lower initial fluoride concentration is better, for example, and the fluoride concentration of W3 was $8.6 \mathrm{mg} / \mathrm{L}$, relating to a highest removal efficiency of $80.67 \%$. However, once the optimal removal efficiency was acquired with such high adsorbent dose, the adsorption capacity inevitably decreased and was significantly lower than the adsorbents of other studies. In order to make the results of this study comparable to the others, the adsorbent dose was drastically reduced to $2 \mathrm{~g} / \mathrm{L}$ to acquire a satisfy adsorption capacity. As a result, the harvested maximum adsorption capacity was $2.03 \mathrm{mg} / \mathrm{g}$ appearing at adsorption processes in W1 sample, which is lower than composite adsorbent, desugared reed root, and lignite from other literatures, while higher than pumice, modified montmorillonite, modified hematite, and modified zeolite (Table 10). Of course, its greatly decreased removal efficiency (only $20.10 \%$ ) was foreseeable.

Table 9. The adsorption capacity of HWS for three water samples with different adsorbent doses.

\begin{tabular}{|c|c|c|c|c|}
\hline Adsorbent & Adsorbent Dose (g/L) & Initial Concentration (mg/L) & Adsorption Capacity (mg/g) & Removal Efficiency (\%) \\
\hline \multirow{6}{*}{ HWS } & 2.00 & 2.40 & 0.625 & 52.08 \\
\hline & 14.10 & $20.20(\mathrm{~W} 1)$ & 1.135 & 79.23 \\
\hline & 2.00 & $20.00(\mathrm{~W} 1)$ & 2.030 & 20.10 \\
\hline & 14.10 & 15.30 (W2) & 0.866 & 79.81 \\
\hline & 2.00 & $15.30(\mathrm{~W} 2)$ & 1.940 & 25.36 \\
\hline & 14.10 & $8.60(\mathrm{~W} 3)$ & 0.492 & 80.67 \\
\hline
\end{tabular}

Table 10. Comparison of properties between HWS adsorbent and other adsorbents.

\begin{tabular}{ccccc}
\hline Adsorbent & Adsorbent Dose (g/L) & Initial Concentration (mg/L) & Adsorption Capacity (mg/g) & Reference \\
\hline Composite & 1.5 & 5.24 & 3.07 & {$[42]$} \\
absorbent & 2.29 & 2.8 & 0.31 & {$[43]$} \\
Pumice & 0.1 & 2.4 & 2.136 & {$[44]$} \\
Desugared reed & 3 & 90 & 6.9 & {$[45]$} \\
root & 1 & 10 & 0.696 & {$[46]$} \\
Lignite & - & 5.8 & 0.53 & {$[47]$} \\
Modified & - & 0.1 & 1.766 & {$[38]$} \\
montmorillonite & 2.0 & $20.2(\mathrm{~W} 1)$ & 2.03 & This study \\
Modified hematite & & &
\end{tabular}

\section{Conclusions}

This work has shown that WS can be considered as a promising material for removing fluoride from poor quality water. The conclusions drawn from this study are given below:

(1) Acid treatment and high temperature ranges found as the conditions for better fluoride sorption and hydrochloric acid treatment will gain the best efficiency for removing fluoride for WS.

(2) A model of adsorption has been proposed for the adsorption of $\mathrm{F}^{-}$onto HWS. The results gained from this study were well described by the theoretical Langmuir isotherms. The values of the equilibrium parameter and RL indicated that the $\mathrm{F}^{-}$/treated HWS system was favorable. Kinetic studies reveal that the adsorption is first order. Thermodynamic parameters were calculated, indicating that the adsorption was spontaneous. 
(3) RSM based on BBD was employed to investigate the effects of the three independent variables, namely, HWS dose, $\mathrm{pH}$, and initial concentration on the adsorption of fluoride by HWS. The optimum removal efficiency of fluoride from wastewater using HWS was observed with the help of RSM, and it can reach $81.153 \%$ under the optimum condition: HWS dose of $14.10 \mathrm{~g} / \mathrm{L}$, at $\mathrm{pH}=6.12$.

(4) In addition, the results showed that presence of other co-exiting ions, such as $\mathrm{SO}_{4}{ }^{2-}, \mathrm{PO}_{4}{ }^{3-}$, $\mathrm{SiO}_{4}{ }^{4-}$, and $\mathrm{NO}_{3}{ }^{-}$anions show a negative effect on the removal of fluoride to varying degrees, in the order $\mathrm{SiO}_{4}{ }^{4-}>\mathrm{PO}_{4}{ }^{3-}>\mathrm{SO}_{4}{ }^{2-}>\mathrm{NO}_{3}{ }^{-}$.

Acknowledgments: The project was supported by the National Natural Science Foundation of China (No. 41672224 and No. 41472220), the National Key Research and Development Program of China (No. 2016YFC0400701), the China Geological Survey (No. 121201011000150021), the open fund of Key Laboratory of Subsurface Hydrology and Ecological Effect in Arid Region of Ministry of Education (No. 300102298502), Henan province transportation science and technology project (No. 2017J4-1).

Author Contributions: This paper represents a result of collaborative teamwork. Ying Li and Shengke Yang conceived and designed the experiments, Qianli Jiang wrote the manuscript, Jie Fang analyzed the data and drew figures, and Wenke Wang and Yanhua Wang provided constructive suggestions for the manuscript. The authors contributed equally to this work.

Conflicts of Interest: The authors declare no conflict of interest.

\section{References}

1. Ozsvath, D.L. Fluoride and environmental health: A review. Rev. Environ. Sci. Biol. 2008, 8, 59-79. [CrossRef]

2. Velazquez-Jimenez, L.H.; Hurt, R.H.; Matos, J.; Rangel-Mendez, J.R. Zirconium-carbon hybrid sorbent for removal of fluoride from water: Oxalic acid mediated $\mathrm{Zr}(\mathrm{IV})$ assembly and adsorption mechanism. Environ. Sci. Technol. 2014, 48, 1166-1174. [CrossRef] [PubMed]

3. Mohapatra, M.; Anand, S.; Mishra, B.K.; Giles, D.E.; Singh, P. Review of fluoride removal from drinking water. J. Environ. Manag. 2009, 91, 67-77. [CrossRef] [PubMed]

4. Aoudj, S.; Drouiche, N.; Hecini, M.; Ouslimane, T.; Palaouane, B. Coagulation as a Post-Treatment Method for the Defluoridation of Photovoltaic Cell Manufacturing Wastewater. Procedia Eng. 2012, 33, 111-120. [CrossRef]

5. Tor, A. Removal of fluoride from water using anion-exchange membrane under Donnan dialysis condition. J. Hazard. Mater. 2007, 141, 814-818. [CrossRef] [PubMed]

6. Ho, L.N.; Ishihara, T.; Ueshima, S.; Nishiguchi, H.; Takita, Y. Removal of fluoride from water through ion exchange by mesoporous Ti oxohydroxide. J. Colloid Interface Sci. 2004, 272, 399-403. [CrossRef] [PubMed]

7. Tripathy, S.S.; Bersillon, J.L.; Gopal, K. Removal of fluoride from drinking water by adsorption onto alum-impregnated activated alumina. Sep. Purif. Technol. 2006, 50, 310-317. [CrossRef]

8. Yu, X.L.; Tong, S.R.; Ge, M.F.; Zuo, J.C. Removal of fluoride from drinking water by cellulose @ hydroxyapatite nanocomposites. Carbohyd. Polym. 2013, 92, 269-275. [CrossRef] [PubMed]

9. Pan, B.C.; Xu, J.S.; Wu, B.; Li, Z.G.; Liu, X.T. Enhanced removal of fluoride by polystyrene anion exchanger supported hydrous zirconium oxide nanoparticles. Environ. Sci. Technol. 2013, 47, 9347-9354. [CrossRef] [PubMed]

10. Fan, X.; Parker, D.J.; Smith, M.D. Adsorption kinetics of fluoride on low cost materials. Water Res. 2003, 37, 4929-4937. [CrossRef] [PubMed]

11. Márquez-Mendoza, S.; Jiménez-Reyes, M.; Solache-Ríos, M.; Gutiérrez-Segura, E. Fluoride removal from aqueous solutions by a carbonaceous material from pyrolysis of sewage sludge. Water Air Soil Pollut. 2012, 223, 1959-1971. [CrossRef]

12. Ghorai, S.; Pant, K.K. Equilibrium, kinetics and breakthrough studies for adsorption of fluoride on activated alumina. Sep. Purif. Technol. 2005, 42, 265-271. [CrossRef]

13. Xu, Y.M.; Ning, A.R.; Zhao, J. Preparation and defluorination performance of activated cerium(IV) oxidesimcm-41 adsorbent in water. J. Colloid Interface Sci. 2001, 235, 66-69. [CrossRef] [PubMed]

14. Wajima, T.; Umeta, Y.; Narita, S.; Sugawara, K. Adsorption behavior of fluorideions using a titanium hydroxide-derived adsorbent. Desalination 2009, 113, 1027-1035. [CrossRef]

15. Turner, B.D.; Binning, P.; Stipp, S.L.S. Fluoride removal by calcite: Evidence for fluorite precipitation and surface adsorption. Environ. Sci. Technol. 2005, 39, 9561-9568. [CrossRef] [PubMed] 
16. Hu, Y.S.; Zhao, Y.Q.; Zhao, X.H.; Jeyakumar, L. High Rate Nitrogen Removal in an Alum Sludge-Based Intermittent Aeration Constructed Wetland. Environ. Sci. Technol. 2012, 46, 4583-4590. [CrossRef] [PubMed]

17. Sujana, M.G.; Thakur, R.S.; Rao, S.B. Removal of Fluoride from aqueous solution by using alum sludge. J. Colloid Interface Sci. 1998, 206, 94-101. [CrossRef] [PubMed]

18. Kim, Y.S.; Kim, D.H.; Yang, J.S.; Baek, K. Adsorption Characteristics of As(III) and As(V) on Alum Sludge from Water Purification Facilities. Sep. Sci. Technol. 2012, 47, 2211-2217. [CrossRef]

19. Razali, M.; Zhao, Y.Q.; Bruen, M. Effectiveness of a drinking-water treatment sludge in removing different phosphorus species from aqueous solution. Sep. Purif. Technol. 2007, 55, 300-306. [CrossRef]

20. Wajima, T.; Rakovan, J.F. Removal of fluoride ions using calcined paper sludge. J. Therm. Anal. Calorim. 2013, 113, 1027-1035. [CrossRef]

21. Nair, A.T.; Ahammed, M.M. The reuse of water treatment sludge as a coagulant for post-treatment of UASB reactor treating urban wastewater. J. Clean. Prod. 2013, 96, 272-281. [CrossRef]

22. Wahab, M.A.; Jellali, S.; Jedidi, N. Ammonium biosorption onto sawdust: FTIR analysis, kinetics and adsorption isotherms modeling. Bioresour. Technol. 2010, 101, 5070-5075. [CrossRef] [PubMed]

23. Lv, L.; He, J.; Wei, M.; Evans, D.G.; Zhou, Z. Treatment of high fluoride concentration water by $\mathrm{MgAl}_{-} \mathrm{CO}_{3}$ layered double hydroxides: Kinetic and equilibrium studies. Water Res. 2007, 41, 1534-1542. [CrossRef] [PubMed]

24. Nigussie, W.; Zewge, F.; Chandravanshi, B.S. Removal of excess fluoride from water using waste residue from alum manufacturing process. J. Hazard. Mater. 2007, 147, 954-963. [CrossRef] [PubMed]

25. Zhang, H.; Li, Y.; Wu, X. Statistical experiment design approach for the treatment of landfill leachate by photoelectro-Fenton process. J. Environ. Eng. 2012, 138, 278-285. [CrossRef]

26. Nair, A.T.; Makwana, A.R.; Ahammed, M.M. The use of response surface methodology for modelling and analysis of water and wastewater treatment processes: A review. Environ. Sci. Technol. 2014, 69, 464-478. [CrossRef] [PubMed]

27. Cheng, D.H.; Yang, S.K.; Zhao, Y.; Chen, J. Adsorption behaviors of Oxytetracycline onto sediment in the Weihe River, Shaanxi, China. J. Chem. 2013, 2013, 719-723. [CrossRef]

28. Zhao, Y.; Yang, S.K.; Wang, G.; Han, M. Adsorption behaviors of Acetaminophen onto the colloid in sediment. Pol. J. Environ. Stud. 2015, 24, 411-419. [CrossRef]

29. Cengeloĝlu, Y.; Kir, E.; ErsÖz, M. Removal of fluoride from aqueous solution by using red mud. Sep. Purif. Technol. 2006, 51, 374-378. [CrossRef]

30. Gopal, V.; Elango, K.P. Equilibrium, kinetic and thermodynamic studies of adsorption of fluoride onto plaster of Paris. J. Hazard. Mater. 2007, 141, 98-105. [CrossRef] [PubMed]

31. Samarghandi, M.R.; Khiadani, M.; Foroughi, M.; Nasab, H.Z. Defluoridation of water using activated alumina in presence of natural organic matter via response surface methodology. Environ. Sci. Pollut. R. 2016, 23, 887-897. [CrossRef] [PubMed]

32. Bashir, M.J.; Isa, M.H.; Kutty, S.R.M.; Awang, Z.B.; Aziz, H.A.; Mohajeri, S. Landfill leachate treatment by electrochemical oxidation. Waste Manag. 2009, 29, 2534-2541. [CrossRef] [PubMed]

33. Mohajeri, S.; Aziz, H.A.; Isa, M.H.; Zahed, M.A.; Adlan, M.N. Statistical optimization of process parameters for landfill leachate treatment using electro-Fenton technique. J. Hazard. Mater. 2010, 176, 749-758. [CrossRef] [PubMed]

34. Moghaddam, S.S.; Moghaddam, M.R.A.; Arami, M. Coagulation/flocculation process for dye removal using sludge from water treatment plant: Optimization through response surface methodology. J. Hazard. Mater. 2010, 175, 651-657. [CrossRef] [PubMed]

35. Sundaram, C.S.; Viswanathan, N.; Meenakshi, S. Defluoridation chemistry of synthetic hydroxyapatite at nano scale: Equilibrium and kinetic studies. J. Hazard. Mater. 2008, 155, 206-215. [CrossRef] [PubMed]

36. Gao, S.; Cui, J.; Wei, Z. Study on the fluoride sorption of various apatite materials in aqueous solution. J. Fluor. Chem. 2009, 130, 1035-1041. [CrossRef]

37. Kumar, E.; Bhatnagar, A.; Kumar, U.; Sillanpää, M. Defluoridation from aqueous solutions by nano-alumina: Characterization and sorption studies. J. Hazard. Mater. 2011, 186, 1042-1049. [CrossRef] [PubMed]

38. Zhang, Z.J.; Tan, Y.; Zhong, M.F. Defluorination of wastewater by calcium chloride modified natural zeolite. Desalination 2011, 276, 246-252. [CrossRef] 
39. Mourabet, M.; Rhilassi, A.E.; Boujaady, H.E.; Bennani-Ziatni, M.; Hamri, R.E.; Taitai, A. Removal of fluoride from aqueous solution by adsorption on apatitic tricalcium phosphate using box-behnken design and desirability function. Appl. Surf. Sci. 2012, 258, 4402-4410. [CrossRef]

40. Kamble, S.P.; Jagtap, S.; Labhsetwar, N.K.; Thakare, D.; Godfrey, S.; Devotta, S.; Rayalu, S.S. Defluoridation of drinking water using chitin, chitosan and lanthanum-modified chitosan. Chem. Eng. Sci. 2007, 129, 173-180. [CrossRef]

41. Vinitnantharat, S.; Kositchaiyong, S.; Chiarakorn, S. Removal of fluoride in aqueous solution by adsorption on acid activated water treatment sludge. Appl. Surf. Sci. 2010, 256, 5458-5462. [CrossRef]

42. Chen, J.X.; Chen, H.H.; Li, X.H.; He, X.J. Preparation and application of zirconium-modified chitosan-zeolitekaolin composite absorbent for fluoride removal from water. J. Environ. Health 2017, 34, 61-66. (In Chinese)

43. Malakootian, M.; Moosazadeh, M.; Yousefi, N.; Fatehizadeh, A. Fluoride removal from aqueous solution by pumice: Case study on Kuhbonan water. Afr. J. Environ. Sci. Technol. 2011, 5, 299-306.

44. Song, R.; Yang, S.K.; Xu, H.Y.; Wang, Z.Z.; Chen, Y.Y.; Wang, Y.Y. Adsorption Behavior and Mechanism for the Uptake of Fluoride Ions by Reed Residues. Int. J. Environ. Res. Public Health 2018, 15, 101. [CrossRef] [PubMed]

45. Zhou, C.Q.; Deng, X.H.; Liu, H.M.; Li, Z.W. Treatment of aqueous solution containing fluoride by absorption process. Technol. Water Treat. 2006, 32, 1-5. (In Chinese)

46. Bia, G.; de Pauli, C.P.; Borgnino, L. The role of Fe(III)modified montmorillonite on fluoride mobility: Adsorptionexperiments and competition with phosphate. J. Environ. Manag. 2012, 100, 1-9. [CrossRef] [PubMed]

47. Teutli-Sequeira, A.; Martı'nez-Miranda, V.; Solache-Rı'os, M.; Linares-Herna'ndez, I. Aluminum and lanthanum effects in natural materials on the adsorption of fluoride ions. J. Fluor. Chem. 2013, 148, 6-13. [CrossRef]

(C) 2018 by the authors. Licensee MDPI, Basel, Switzerland. This article is an open access article distributed under the terms and conditions of the Creative Commons Attribution (CC BY) license (http:/ / creativecommons.org/licenses/by/4.0/). 